\title{
-Originals-
}

\section{Veins of the lumbar spinal ganglia in human adults and fetuses}

\author{
Masahiko Takano ${ }^{1)}$, Kumiko Tanuma ${ }^{1)}$, Hironobu Ito ${ }^{1)}$ and Yasumasa Shirai ${ }^{2)}$ \\ ${ }^{1)}$ Department of Anatomy, Nippon Medical School \\ ${ }^{2)}$ Department of Orthopaedic Surgery, Nippon Medical School
}

\begin{abstract}
To obtain a fundamental knowledge of the morphological relationship between nerve root symptoms and circulatory disorders, the distribusion pattern of the veins in the lumbar spinal ganglia from the first to fifth vertebrae was investigated in 5 adult human cadavers (mean age 69.6 years) and 5 human fetuses (mean age 6.6 months).

The following results were obtained:

1) In the adults the veins perforating from the outer surface of the fifth lumbar spinal ganglion were smaller in number than those perforating from the first to fourth ganglia. In contrast, in the fetuses the number of such veins was increased in the lower lumbar spinal ganglia. In each of the ganglia, the number of veins emerging through the dorsal side was much higher than the number perforating from the outer surface of the ventral sides. The veins perforating through the outer surface of the ganglion formed weak venous networks (periganglionic venous plexus) surrounding the dorsal ramus of the spinal nerve.

2) The veins communicating with the tributaries from the periganglionic venous plexus were classified into three types. Type 1 veins flowed into the intervertebral veins (the frequency ranged from 9.2 to 18.2 in the adults and from 22.4 to 37.0 in the fetuses). Type 2 veins coursed in the spinal cord along the dorsal root fibers and penetrated the dura mater on the way (the frequency ranged from 0.4 to 4.8 in the adults and from 1.2 to 2.2 in the fetuses). Type 3 veins opened directly into the internal vertebral plexus (the frequency ranged from 0.4 to 1.8 in the adults and from 0 to 0.4 in the fetuses). Type 1 veins were the most frequent among the three types of veins in both adults and fetuses. Few type 3 veins were observed in either group.

3) In the first and second lumbar vertebrae in the adults, three-quarters of each spinal ganglion was situated in the vertebral canal. In the lower lumbar region ( L 3 - L 5), three quarters of each spinal ganglion lay on the outside of the vertebral canal. In the fetuses, approximately one half to three-quarters of each lumbar spinal ganglion was located in the vertebral canal. (J Nippon Med Sch 1998; 65: 298-306)
\end{abstract}

Key words: vein, lumbar spinal ganglion, fetus, internal vertebral venous plexus, periganglionic venous plexus

Correspondence to Masahiko Takano, Department of Anatomy, Nippon Medical School, 1-1-5 Sendagi, Bunkyo-ku, Tokyo 113-8602, Japan

Abbreviations: AIVVP; Anterior internal vertebral venous pleuxs, ALV; Ascending lumbar vein, DD; Dorsal primary division of the spinal nerve, D; Dura mater, SG; Spinal ganglion, EVVP; External vertebral venous plexus, IF; Intervertebral foramen, IV; Intervertebral vein, LV; lumbar vein, P; Pedicle, PIVVP; Posterior internal verbebral venous plexus, PLL; Posterior longitudinal ligament, PP; Periganglionic venous plexus 


\section{Introduction}

It has been conjectured that circulatory disorders in the peripheries of the nerve roots, as well as mechanical pressure on the roots, contribute to the nerve root symptoms that appear in lumbar degeneration $^{1-10}$. Many fundamental studies of the behavior and morphology of the blood vessels around the nerve roots have been performed to investigate the mechanisms of these circulatory disorders ${ }^{11-20}$. According to Bergmann et al. ${ }^{11}$, the veins of the spinal ganglia open into spinal periganglionic venous plexuses, and the branches from these plexuses open into the intervertebral veins. However, there have been no studies focusing on the geographical distribution pattern of the veins in the lumbar region, although there are several relevant clinically oriented papers. Blau et al. ${ }^{1}$, Evans ${ }^{2}$, and Wilson et $\mathrm{al}^{3}{ }^{3}$ proposed that lumbar pain is due to causes in the arterial system, while Kavanaugh ${ }^{4}$ and $\mathrm{Hanai}^{5}$ believed that lumbar pain is caused in the venous system. In addition to these studies, experiments have been performed on by using pigs ${ }^{6}$ and $\operatorname{dogs}^{7}$ from the point of view of clinical pathology. These reports support the opinion ${ }^{8}$ that venous circulation surrounding the spinal column has a great deal to do with the appearance of nerve root symptoms.

With the background, we investigated the venous morphology of the lumbar spinal ganglia and the nerve roots in human fetuses and adult cadavers. The findings obtained in this study showed that the veins in the lumbar spinal ganglia could be classified into three types according to their distribution pattern, and the number of veins in each type was distinctly different between the adults and fetuses.

(This study was approved by the Ethics Committee of Nippon Medical School on February 20, 1995.)

\section{Materials and Methods}

The study materials were 5 Japanese adult cadavers ( 3 males, 2 females; ages $62-87$, mean 69.6 ) and 5 Japanese fetuses ( 2 males, 3 females; $6^{-7}$ months, mean 6.6 months). The vena azygos and the inferior vena cava were exposed and severed, and dyed latex was manually injected into each vein.
After the injected agent polymerized, a laminectomy was performed and soft tissues around the vertebrae were removed. The L 1-L 5 spinal ganglia and the venous arrangement surrounding them were then dissected. In addition, a resincasting of blood vessels was also made by injection of acrylic resin as a reference for vascular architecture around the spinal ganglia. The origins, courses, and distribution of branches of the blood vessels were examined under a dissecting microscope. The sites of observation included 50 bilateral regions in the adult cadavers and 50 bilateral regions in the fetuses, in the L 1-L 5 spinal ganglia.

\section{Results}

1. Veins distributed in the lumbar spinal ganglia in adult cadavers

Many veins draining through the ganglia flowed into the venous plexuses surrounding the ganglia (periganglionic venous plexuses) ${ }^{11}$ or the intervertebral veins. These periganglionic venous plexuses were denser at the sites which surrounded the dorsal ramus of the spinal nerves. A few veins flowed directly into the internal vertebral venous plexus without going through these periganglionic venous plexuses, or ran to the spinal cord along the nerve root. We counted the number of veins penetrating the ganglia as the number of veins distributed in these ganglia.

1) Numbers of veins distributed in the ganglia

Table 1 shows the numbers of veins which appeared outside the ganglia from $\mathrm{L} 1$ to $\mathrm{L} 5$. The numbers of veins at each height at L 1-L 4 ranged from 17.4 to 22.2 , but at $L 5$, on both sides, the numbers were smaller than the minimum number at L 1-L 4 .

The numbers of veins penetrating the ganglia on the dorsal side were greater than those of vein outlets on the ventral side in all lumbar spinal ganglia (Table 1).

2) Tributaries of the lumbar spinal ganglionic veins

The veins that were distributed in the spinal ganglia were connected with the surrounding veins through more than 10 veins (Fig. 1). As tributaries of them, three types of veins were distinguished. Type 1 veins (Fig. $2 \mathbf{b}$ ) were connected directly to the intervertebral veins, or flowed into the internal 
Table 1 Numbers of veins perforating from the outer surface of the lumbar spinal ganglia in the adult cadavers

\begin{tabular}{l|ccccccc}
\hline & \multicolumn{3}{|c}{ Left } & & \multicolumn{3}{c}{ Right } \\
\cline { 2 - 3 } \cline { 7 - 8 } & Dorsal & Ventral & Total & & Dorsal & Ventral & Total \\
\hline $\mathrm{L}_{1}$ & 13.6 & 6.0 & 19.6 & & 13.4 & 5.6 & 19.0 \\
$\mathrm{~L}_{2}$ & 12.6 & 7.6 & 20.2 & & 11.0 & 6.8 & 17.8 \\
$\mathrm{~L}_{3}$ & 13.6 & 6.2 & 19.8 & & 13.8 & 6.2 & 20.0 \\
$\mathrm{~L}_{4}$ & 11.6 & 5.8 & 17.4 & & 14.0 & 8.2 & 22.2 \\
$\mathrm{~L}_{5}$ & 7.4 & 4.2 & 11.6 & & 9.0 & 5.6 & 14.6 \\
\hline
\end{tabular}

The data shown are means of five cadavers.

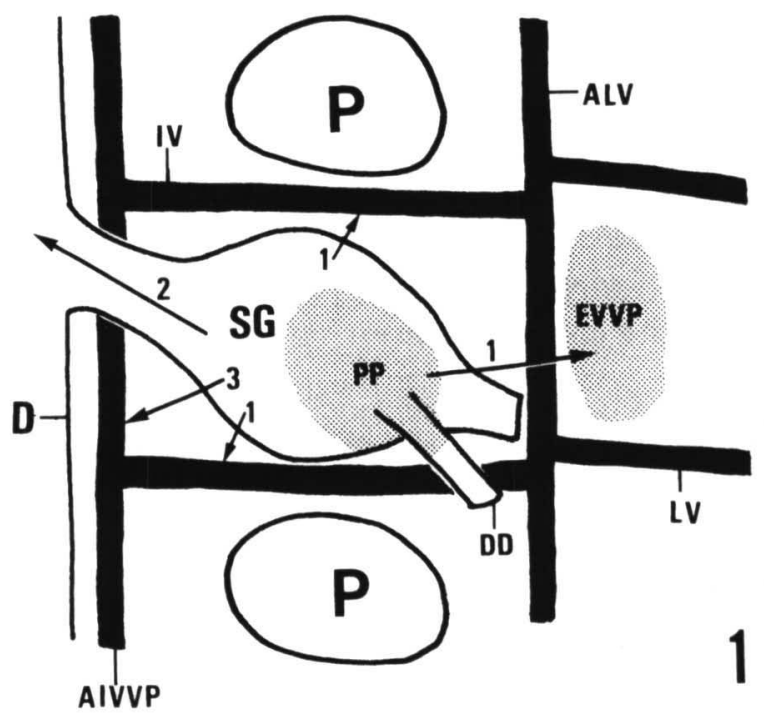

Fig. 1 Schema of the communicating branches with the surrounding veins and the periganglionic venous plexus or ganglionic veins 1: Type 1 veins, 2: Type 2 veins, 3 : type 3 veins

and external vertebral venous plexuses through the periganglionic venous plexuses (Fig. 2a, PP). Type 2 veins (Fig. 3) lay along the nerve roots toward the spinal cord and penetrated the dura mater on the way to the spinal cord. Type 3 veins (Fig. 4) opened directly into the internal vertebral venous plexuses. Type 1 veins were the most numerous at all heights from L 1 to L 5 (Table 2). The mean number of Type 1 veins at L 1 - L 5 was 14.9 , that of Type 2 veins was 2.2 , and that of Type 3 veins was 1.1 . There were thus very few Type 2 and Type 3 veins. The internal vertebral plexuses are formed from anterior and posterior internal vertebral plexuses; the former were denser than the latter (Fig. 2a). The veins which were distributed in the various ganglia were connected by way of the internal and external vertebral venous plexuses, which formed a vertical row.

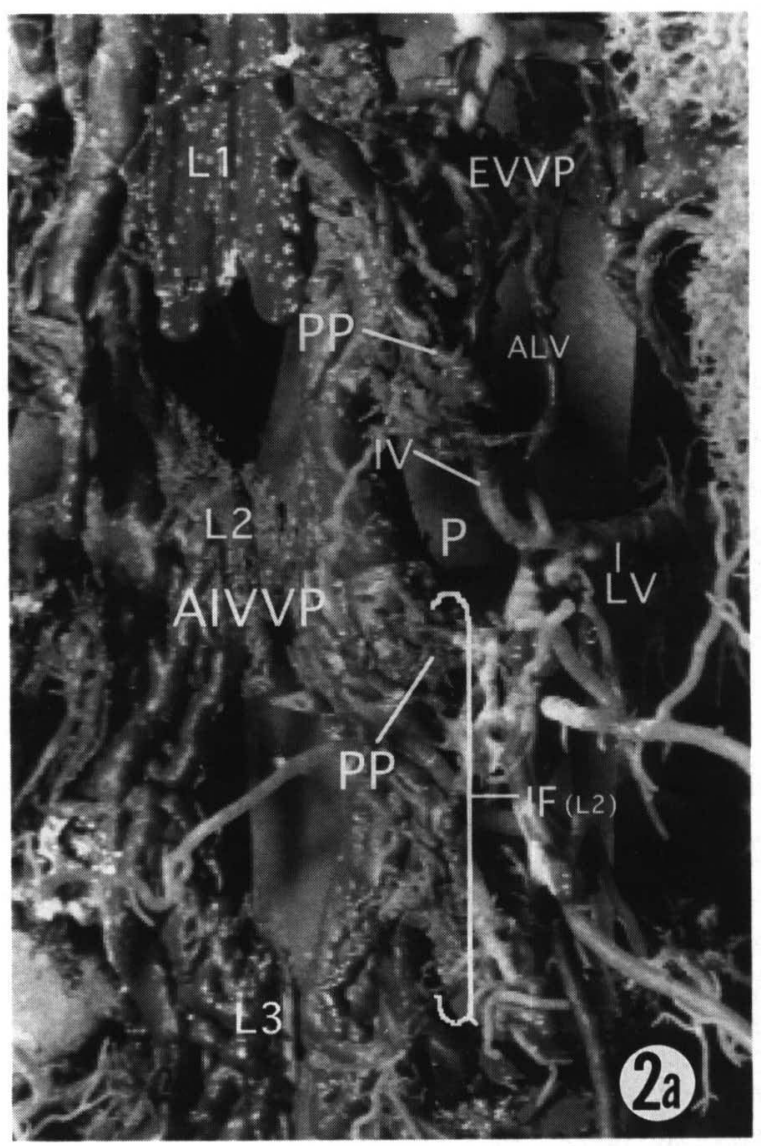

Fig. 2a Corrosion casting specimens of the internal and external vertebral venous plexus and periganglionic venous plexus. (dorsal view)

\section{3) Positions of spinal ganglia}

The lumbar spinal ganglia became gradually larger from the highest to the lowest spinal level. As a result, the lower ganglia, compared to the higher ones, were situated in sach a way that they cut across the intervertebral foramina in a more inclined formation. Approximately $3 / 4$ of each ganglion was within the vertebral canal at the $\mathrm{L} 1$ and L 2 levels, and approximately 1/4 was within the vertebral canal at the L 3-L 5 levels (Fig. 5). 


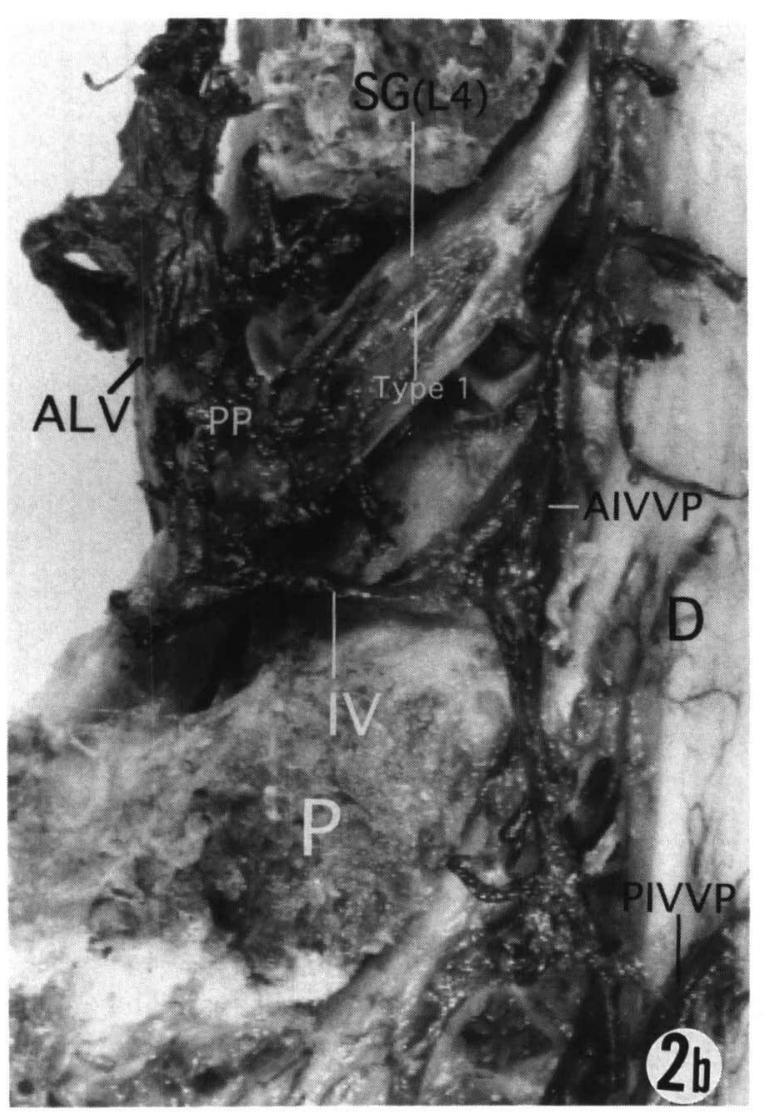

Fig. 2b Venous supply of a spinal ganglion in an adult containing type 1 vein. (Type 1)

\section{Veins distributed in the lumbar spinal gan-} glia in the fetuses

1) Numbers of veins distributed in the ganglia

The veins distributing in the lumbar spinal ganglia were investigated by the same method as that used for the adult cadavers. The mean number of veins penetrating the ganglia and appearing outside them increased from the upper to the lower lumbar vertebrae, except for $\mathrm{L} 5$, on the right side (Table 3).

Slightly more veins appeared on the dorsal side than on the ventral side at each level, except for L 2, on the right side (Table 3). At the levels of L 1-L 5, including both left and right sides, the mean number of veins per ganglion was 17.3 on the dorsal side and 15.3 on the ventral side. Thus, a slightly larger number of veins was distributed on the dorsal side.

2) Tributaries of the lumbar spinal ganglionic veins

The veins distributing in the lumbar spinal ganglia were found to be three types. As in the adult cadavers, the Type 1 veins (Fig. 6) were connected directly to the intervertebral veins or to the surrounding veins through the periganglionic venous

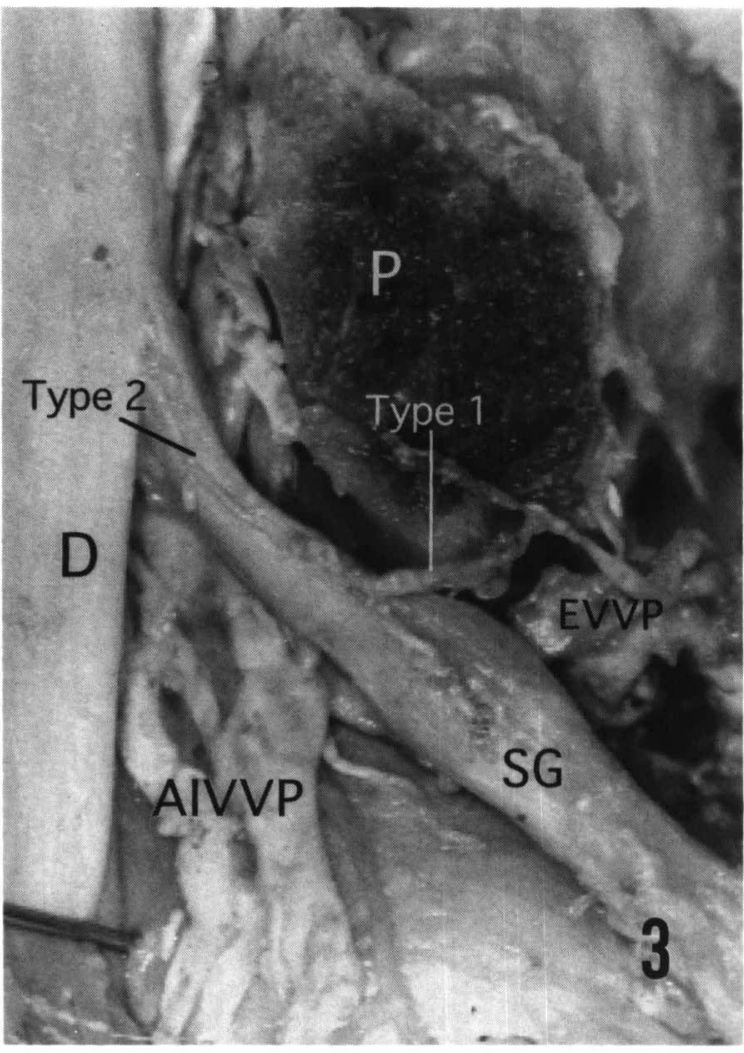

Fig. 3 Venous supply of a spinal ganglion in an adult containing type 1 and type 2 vein. (Type 1 and Type 2)

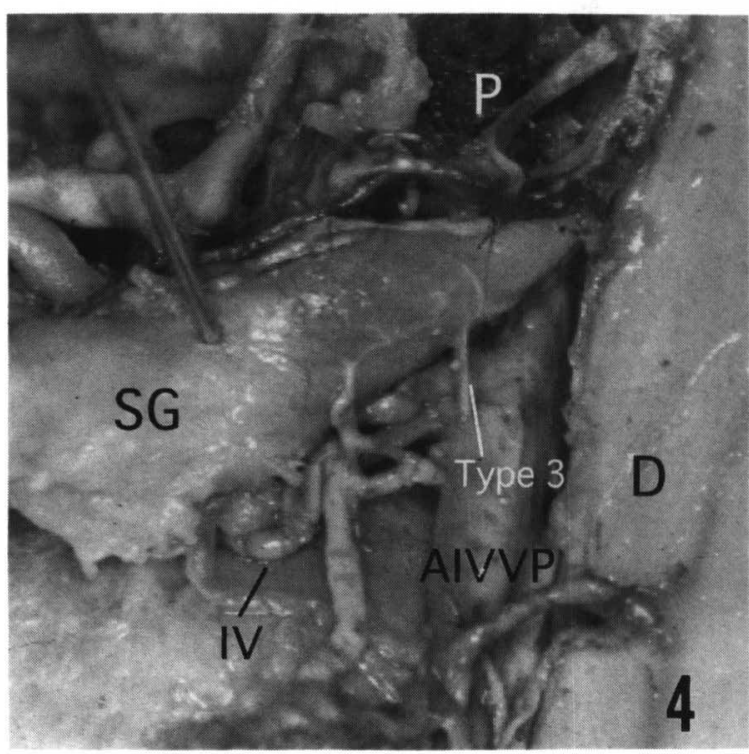

Fig. 4 Venous supply of a spinal ganglion in an adult containing type 3 vein. (Type 3 )

plexuses. Type 2 veins (Fig. 7) lay along the nerve roots, toward the proximal part of the spinal cord, and penetrated the dura mater on the way to the spinal cord. Type 3 veins (Fig. 7) communicated directly with the internal vertebral venous plexuses. The Type 1 veins were the most numerous at all 
Table 2 Types and numbers of the veins communicating with the tributaries from the periganglionic venous plexus in the adult cadavers

\begin{tabular}{c|ccccccc}
\hline \multirow{2}{*}{ Level } & \multicolumn{3}{|c}{ Left } & & \multicolumn{3}{c}{ Right } \\
\cline { 2 - 3 } \cline { 7 - 8 } & Type 1 & Type 2 & Type 3 & & Type 1 & Type 2 & Type 3 \\
\hline $\mathrm{L}_{1}$ & 17.0 & 1.6 & 1.0 & & 15.4 & 3.2 & 0.4 \\
$\mathrm{~L}_{2}$ & 14.4 & 4.8 & 1.0 & & 13.4 & 3.6 & 0.8 \\
$\mathrm{~L}_{3}$ & 16.4 & 2.4 & 1.0 & & 17.0 & 1.8 & 1.2 \\
$\mathrm{~L}_{4}$ & 16.0 & 0.4 & 1.0 & & 18.2 & 2.2 & 1.8 \\
$\mathrm{~L}_{5}$ & 9.2 & 1.0 & 1.4 & & 12.2 & 1.2 & 1.4 \\
\hline
\end{tabular}

The data shown are means of five cadavers, Type 1 veins flow into branches communicating with the internal and external vertebral plexus. Type 2 veins course in the spinal cord along the dorsal root fibers and penetrate into the dura mater on the way. Type 3 veins open directly into the internal vertebral plexus.

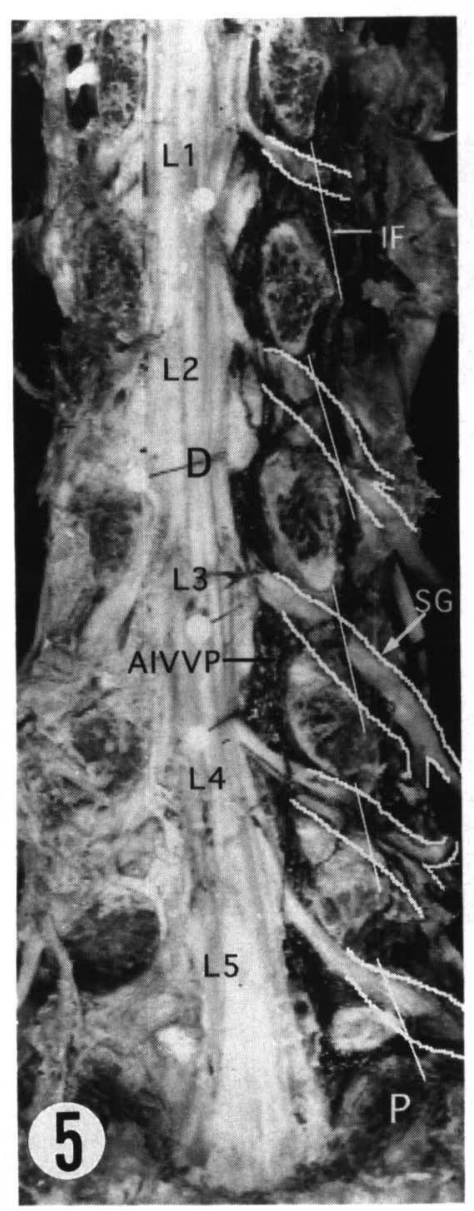

Fig. 5 Position of a lumbar spinal ganglia in an adult (Dorsal view)

lumbar vertebrae (Table 4). The mean numbers of each type per L 1-L 5 ganglion were 30.8 for Type 1, 1.5 for Type 2 , and 0.2 for Type 3 .

In addition, the anterior internal vertebral venous plexuses in the fetuses showed morphologically immature form compared with those in the adults. Rather than plexuses, they showed a similar form to the veins running in a ladder-like fashion inside the vertebral column. These were regarded as an early stage in the formation of the venous plexuses (Fig. 8).

\section{3) Positions of spinal ganglia}

The root fibers in the vertebral canal were short. Approximately 1/2-3/4 of each ganglion at L 1-L 5 was situated within the vertebral canal. The greater part of each ganglion at the higher lumbar level was situated within the vertebral canal (Fig. 9). The spinal ganglia of the thoracic vertebrae were situated within the vertebral canal.

\section{Discussion}

In general, the entering and exiting regions of blood vessels in a certain organ are limited ${ }^{21}$. However, the vessels distributing in the central nervous system are characterized by their vertical entrance or exit at many sites on the superficial layer of the parenchyma $^{22}$. Such a distribution pattern of the blood vessels was also shown in the spinal ganglia by the present study (Tables 1 and 3 and Fig. 2b); the veins drained from many locations within the parenchyma. This kind of structure is unique to the nervous system, which requires a large quantity of blood flow (oxygen); it appears to be a structure which promotes the rapid circulation of blood within the ganglia.

The characteristic of the veins in the ganglia that was common to both the adults and fetuses was that the veins distributed on the dorsal side were more numerous than those distributed on the ventral side. This may be related to the surrounding structures of the ganglia. That is, the ventral sides of the ganglia are in close contact with the vertebral bodies and 
Table 3 Numbers of veins perforating from the outer surface of the lumbar spinal ganglia in the fetuses

\begin{tabular}{c|ccccccc}
\hline \multirow{2}{*}{ Level } & \multicolumn{3}{|c}{ Left } & & \multicolumn{3}{c}{ Right } \\
\cline { 2 - 3 } \cline { 7 - 8 } & Dorsal & Ventral & Total & & Dorsal & Ventral & Total \\
\hline $\mathrm{L}_{1}$ & 13.8 & 13.0 & 26.8 & & 13.4 & 10.6 & 24.0 \\
$\mathrm{~L}_{2}$ & 17.4 & 13.6 & 31.0 & & 14.4 & 14.6 & 29.0 \\
$\mathrm{~L}_{3}$ & 18.4 & 16.4 & 34.8 & & 17.8 & 15.0 & 32.8 \\
$\mathrm{~L}_{4}$ & 18.6 & 18.4 & 37.0 & & 19.8 & 16.2 & 36.0 \\
$\mathrm{~L}_{5}$ & 21.0 & 18.2 & 39.2 & & 18.0 & 17.0 & 35.0 \\
\hline
\end{tabular}

The data shown are means of five fetuses.

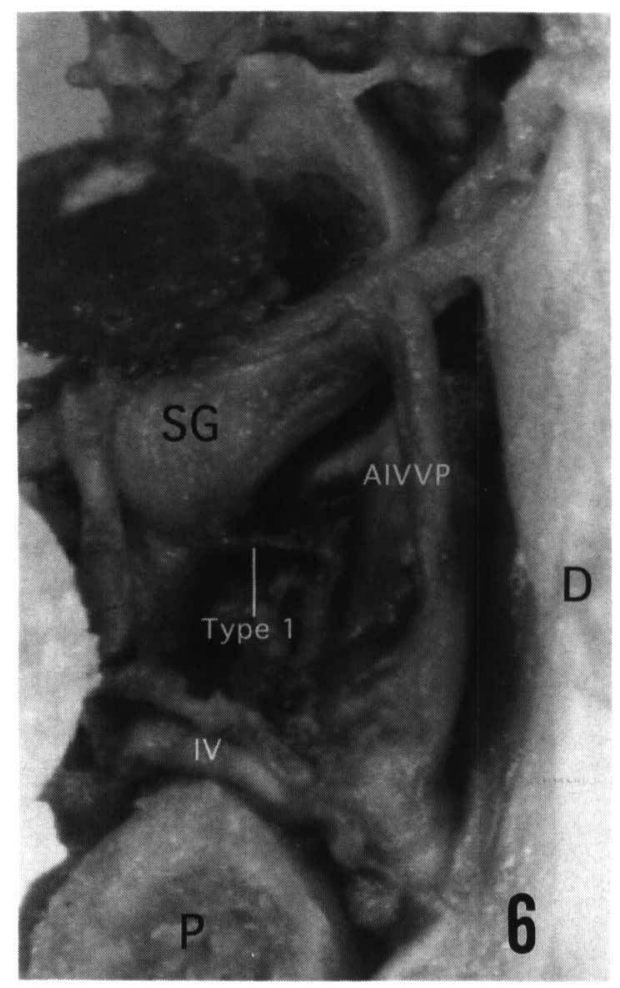

Fig. 6 Venous supply of a spinal ganglion in a fetus containing type 1 vein (Type 1)

the intervertebral disks. The dorsal area of the ganglia, in contrast, is the epidural space containing the blood vessels and fatty tissue within the vertebral canal, and the soft tissues outside the vertebral canal. Therefore, it appears that the dorsal region of ganglia is placed so that the blood flows out in the dorsal direction, because mechanical or physical pressure is not received in this case.

There were two aspects of the distribution of the veins that differed between the adults and the fetuses. In the adults, the numbers of veins distributed at L 1-L 4 were bilaterally similar on both the dorsal and ventral sides. On the other hand, the numbers of veins at L 5 decreased on both dorsal and ventral sides (Table 1). In the fetuses, however,

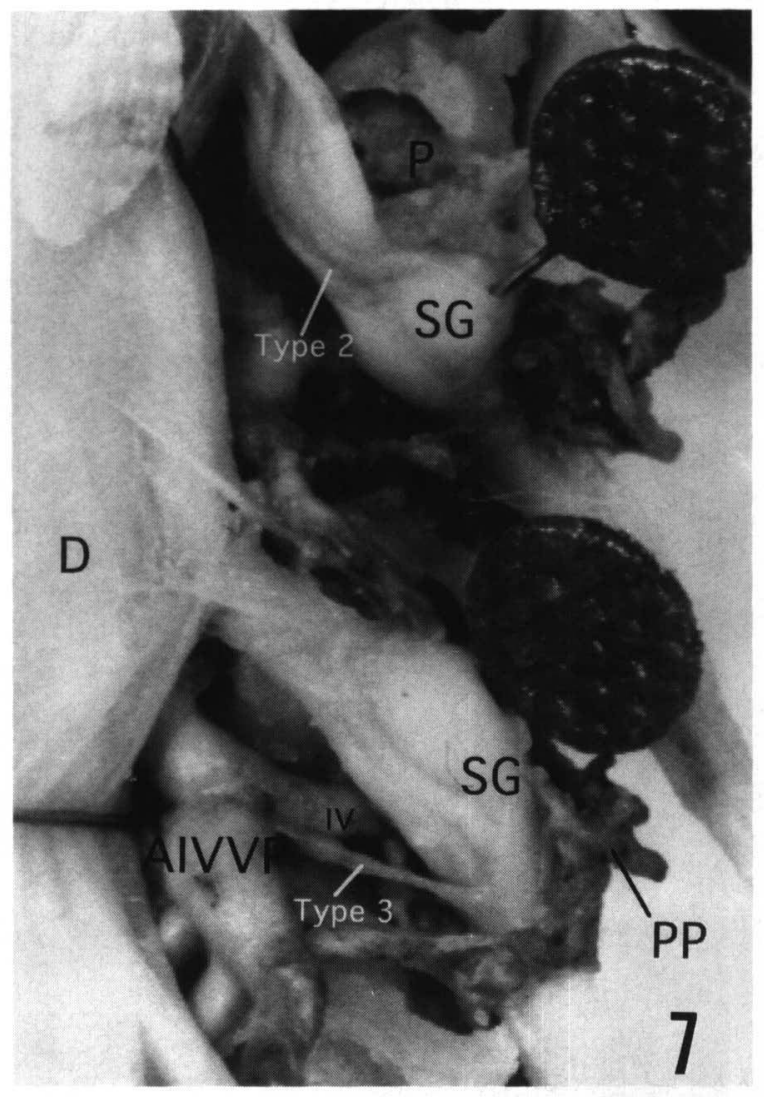

Fig. 7 Venous supply of a spinal ganglia in a fetus containing type 2 and type 3 vein (Type 2 and Type 3)

the numbers of veins tended to increase along the spine from L 1 to L 5 (Table 3). More veins were found at each lumbar spinal ganglion in the fetuses than in the adults, at each level from $\mathrm{L} 1$ to $\mathrm{L} 5$. The reasons for these findings may be, first, that the spinal ganglia of the fetuses were situated in forms which received less physical and mechanical pressure than the spinal ganglia in the adults. Secondly, since the ganglia of the fetuses were at an active growing phase, they required a large quantity of blood, and, of course, the quantity of outflowing blood was also greater. As a result, there were more 
Table 4 Types and numbers of the veins communicating with the tributaries from the periganglionic venous plexus in the fetuses

\begin{tabular}{c|ccccccc}
\hline & \multicolumn{3}{|c}{ Left } & & \multicolumn{3}{c}{ Right } \\
\cline { 2 - 3 } \cline { 7 - 8 } & Type 1 & Type 2 & Type 3 & & Type 1 & Type 2 & Type 3 \\
\hline $\mathrm{L}_{1}$ & 25.6 & 1.2 & 0 & & 22.4 & 1.4 & 0.2 \\
$\mathrm{~L}_{2}$ & 28.4 & 2.2 & 0.4 & & 27.2 & 1.6 & 0.2 \\
$\mathrm{~L}_{3}$ & 33.0 & 1.4 & 0.4 & & 31.2 & 1.2 & 0.4 \\
$\mathrm{~L}_{4}$ & 35.4 & 1.2 & 0.4 & & 34.6 & 1.2 & 0.2 \\
$\mathrm{~L}_{5}$ & 37.0 & 2.2 & 0 & 33.6 & 1.4 & 0 \\
\hline
\end{tabular}

The data shown are means of five fetuses. Type 1 veins flow into branches communicating with the internal and external vertebral plexus. Type 2 veins course in the spinal cord along the dorsal root fibers and penetrate into the dura matter on the way. Type 3 veins open directly into the internal vertebral venous plexus.

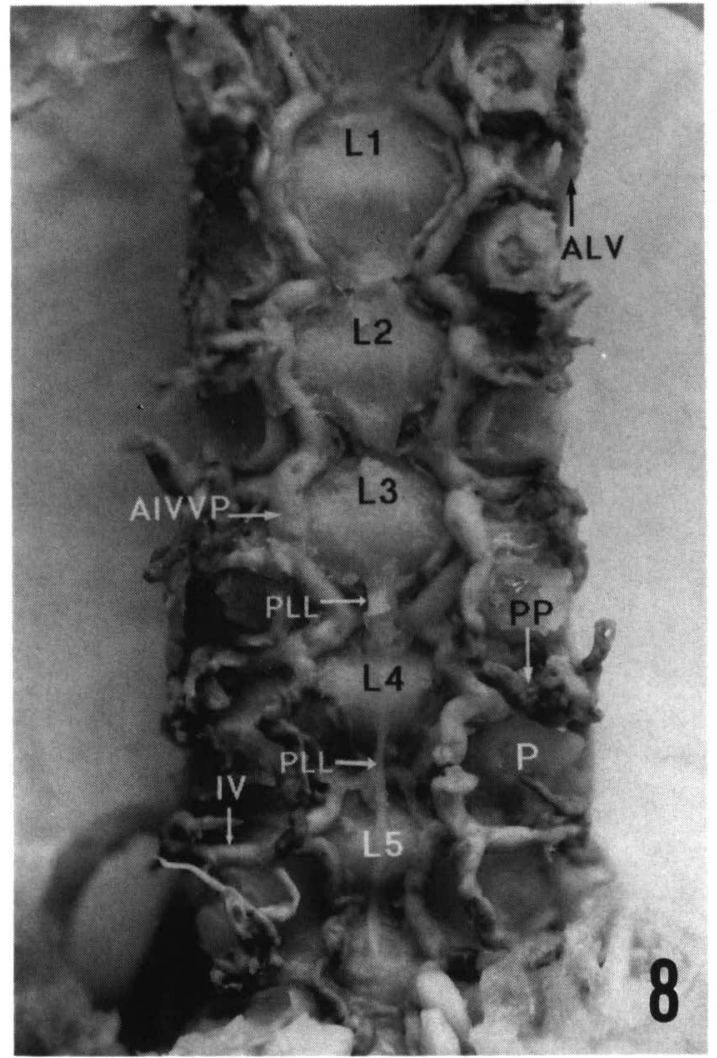

Fig. 8 Anterior intervertebral venous plexus of a fetus

draining veins than in the adults. Yokouchi ${ }^{12}$, who investigated the arteries distributed to the lumbar vertebral ganglia, compared his results with those of Minami ${ }^{13}$, who studied the same phenomenon in fetuses; Yokouchi pointed out that the number of distributed arteries is larger in the fetuses, suggesting a relationship with the growth of the nervous system. On the other hand, Scharf et al. ${ }^{22}$ and Nagashima et al. ${ }^{23}$ reported that the numbers of cells of the ganglia decrease with age. We conjectured that this decrease of nerve cells causes a limita-

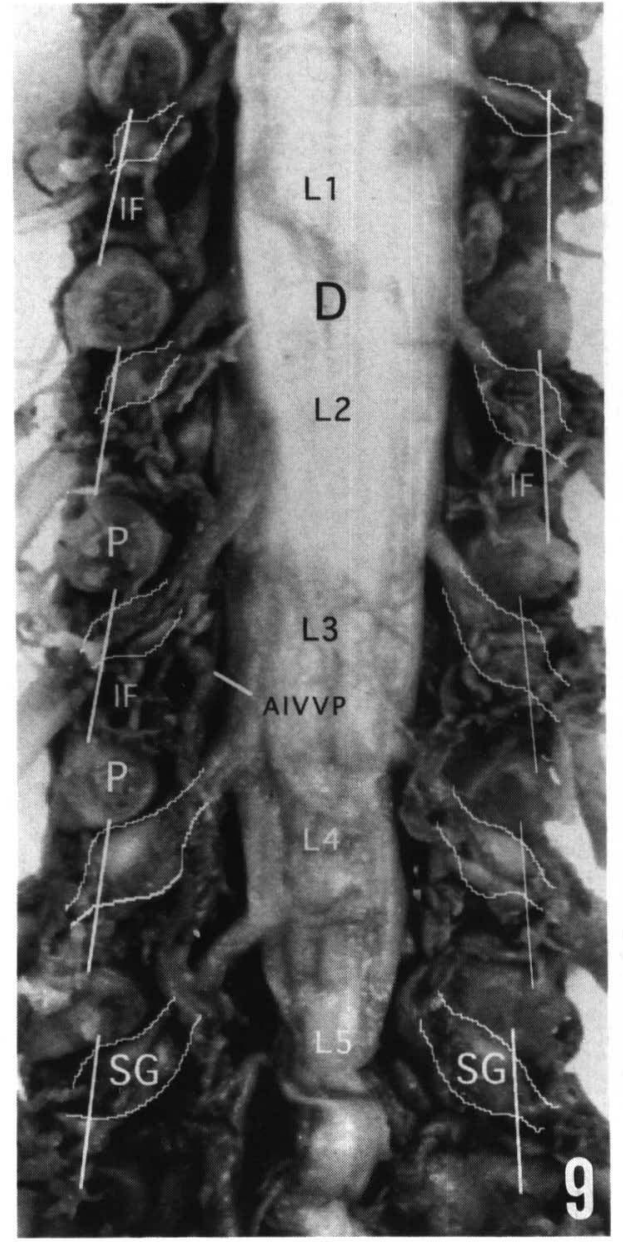

Fig. 9 Position of a lumbar spinal ganglia in a fetus (Dorsal view)

tion of blood flow and the number of distributed veins of the ganglia in adults compared with fetuses. The finding that the number of veins distributed to the L 5 ganglia was smaller than the numbers at L 1-L 4 may be related to the local positions of the spinal ganglia. That is, as was also pointed out by Nagafusa et al. ${ }^{24}$ it was conjectured that most of the 
expansion of the L 5 spinal ganglia is located in a position that receives more pressure than do the L 1-L 4 ganglia. As a result, the number of veins draining from this part of $L 5$ is probably decreased. In the fetus, almost all of the L 5 ganglion $(3 / 4$ of the ganglion) is within the vertebral canal. Therefore, it is thought that the fetal ganglion is not affected to the extent that the adult ganglion is.

We observed that the veins draining the ganglia formed weak venous plexuses surrounding the ganglia. These venous plexuses had the following 4 characteristics: (1) they were denser in the area surrounding the basal parts of the posterior branches of the spinal nerves than they were in other places; (2) the branches of the veins from the venous plexuses surrounding the ganglia opened overwhelmingly into the intervertebral veins in the majority of both the adults and fetuses; (3) they were independent of the internal and external vertebral venous plexuses; and (4) since the ganglia are located both inside and outside the vertebral canal, the venous plexuses were also formed in the corresponding places.

The morphology of the venous plexuses surrounding the ganglia seems, on the positive side, to have a moderating effect on sudden changes in blood pressure and blood flow in the lumbar area ${ }^{25-27}$. On the other hand, since the venous plexuses surrounding the spinal ganglia which are located outside the vertebral canal are embedded in the peripheral muscle tissue groups (psoas major and psoas minor muscles), they are easily affected by these muscle groups. In addition, the venous plexuses surrounding the ganglia communicate with the posterior external vertebral venous plexuses that are embedded in the transversospinal muscles, and appear to be easily affected by these muscles. Therefore, it is thought that the behavior of the blood flow in the periphery of the vertebral column may have a great effect on the venous plexuses surrounding the vertebral ganglia.

\section{References}

1. Blau JN, Logue V: Intermittent claudication of the cauda equina. An unusual syndrome resulting from central protrusion of a lumbar intervertebral disc. Lancet 1961; 20: 1081-1086.
2. Evans JG: Neurogenic intermittent claudication. Brit Med J 1964; 2: 985-987.

3. Wilson CB: Significance of the small lumbar spinal canal: Cauda equina compression syndromes due tospondylosis. Part 3 : Intermittent claudication. J Neurosurg 1969; 31: 499-506.

4. Kavanaugh GJ, Svien HJ, Holman CB, Johnson RM: "Pseudoclaudication" syndrome produced by compression of the cauda equina. J Amer Med Asso 1968; 206: 2477-2481.

5. Hanai $\mathrm{K}$ : Dynamic measurement of intraosseous pressures in lumbar spinal vertebrae with reference to spinal canal stenosis. Spine 1980; 5: 568-574.

6. Olmarker K, Rydevik B, Holm S, Bagge U: Effects of experimental grade compression on blood flow in spinal nerve roots. A vital microscopic study on the porcine cauda equina. J Ortho Res 1989; 7: 817-823.

7. Delamarter RB, Bohlman HH, Dodge LD, Biro C: Experimental lumbar spinal stenosis. J Bone Joint Surg 1990; 72: 110-120.

8. Rydevik B, Brown MD, Lundborg G: Pathoanatomy and pathophysiology of nerve root compression. Spine 1984; 9: 7-15.

9. Verbiest H: A radicular syndromefrom developmental narrowing of the lumbar vertebral canal. J Bone Joint Surg 1954; 36 B: 230-237.

10. Schatzker JS, Pennal GF: Spinal stenosis: A cause of cauda equina compression. J Bone Joint Surg 1968; 50 B: 606-618.

11. Bergmann L, Alexander L: Vascular supply of the spinal ganglia. Arch Neurol. Psychiat 1941; 46: 761-782.

12. Yokouchi M: Morphological studies on the ramus spinalis of the Japanese cadavers by the corrosion casting method. J Nipp Med Sch 1984; 51: 492-510.

13. Minami K: Morphological studies on the spinal rami of the lumbar artery in the Japanese fetus by corrosion-casting method. J Nipp Med Sch 1982; 49: 560-570.

14. Batson OV: The vertebral vein system. Amer J Roentgenol Radium Ther Nucl Med 1957; 78: 195-212.

15. Yoshizawa H, Kobayashi S, Hachiya Y: Blood supply of nerve roots and dorsal root ganglia. Ortho Clin North Amer 1991; 22: 195-211.

16. Crock HV, Yoshizawa H: The blood supply of the vertebral column and spinal cord in man. 1997; pp 101-117, Springer-Verlag, New York.

17. Crock HV, Yamagishi M, Crock MC: The conus medullaris and cauda equina in man. 1986; pp 48-73, Springer-Verlag, Wien, New York.

18. Gray H, Clemente CD: Gray's anatomy (30 th edn) 1985; pp 829-832, Lea \& Febiger, Philadelphia.

19. Miyamoto $H$ : Topographical anatomy of the lumbar artery of the Japanese fetuses. J Nipp Med Sch 1978; 45: 254-262.

20. Ushiyama T: Anatomical study of the radicular vein 
of the cauda equina. J Tokyo Med Sch 1996; 54 120-130.

21. Auer LM, Loew F: The cerebral veins. An experimental and clinical update. 1983; pp 3-38, SpringerVerlag, Wien, New York

22. Scharf JH, Blumenthal HJ: Neuere Aspekte zur Altersabangigen Involution des sensiblen peripheren Nervensystems Z Zellforsch 1967; 78: 280-302.

23. Nagashima K, Oota K: A histopathological study of the human spinal ganglia. 1. Normal variations in aging. Acta Path Jap 1974; 24: 333-344.

24. Nagafusa Y, Kikuchi S: Anatomic and clinical study of lumbosacral nerve roots. Orth Surrg Traumatol
1993; 36: 881-886.

25. Herlihy MF: Revision of the venous system: The role of the vertebral veins. Med J Aust 1947; 1: 661-672.

26. Doommisse GF: The arteries and veins of the human spinal cord from birth. 1975; pp 81-96, Churchill Livingstore Publishers, Edinburgh, London, New York.

27. Theron J, Moret J: Spinal phlebography.1978; pp 105-115 Springer-Verlag, Berlin, Heidelberg, New York.

(Received, February 19, 1998) (Accepted for publication, June 5, 1998) 